\title{
Dampak Ekonomi Makro Terhadap YIELD Surat Berharga Negara: Studi Empiris Di Indonesia
}

\author{
Muhammad Ichsan $^{1^{*}}$, Lestari Agusalim $^{2}$, Zed Abdullah $^{3}$ \\ ${ }^{1}$ Direktorat Jenderal Perbendaharaan, Kementerian Keuangan \\ ${ }^{2,3}$ Universitas Trilogi
}

\section{Informasi Artikel \\ Sejarah artikel: \\ Diterima April 2018 \\ Disetujui Oktober 2018 \\ Dipublikasikan Oktober 2018}

\section{Keywords:}

Macro Economics,

Yield SBN,

VECM

\begin{abstract}
A B S T R ACT
The increasing integration of the world economy and the large share of foreign ownership of the Government Securities (SBN), then changes in economic policies in developed countries affect the pressure on financial markets in emerging market countries. This study analyzes the effect of macroeconomic factors on 10-year tenor Government's yields issued by the Government of Indonesia for the period 2012-2017. Using the Vector Error Correction Model (VECM) results in long-term USD/IDR, Oil Price, Credit Default Swap (CDS) are negatively significant, while Brazilian State Bonds (ON Brazil) have a significant positive effect on SBN yield. Based on the analysis of Impulse Response Function (IRF), the shock of yield on ON Brazil, CDS, JIBOR, USD / IDR and US Treasury (UST) responded positively by the yield SBN in each period, but the shock by Oil Price responded negatively by the yield of $S B N$. The result of Forecast Error Variance Decomposition (FEVD) analysis shows that UST variable is the biggest variable contribution influence to Indonesia SBN yield, followed by $C D S$ and ON Brazil.
\end{abstract}




\section{Pendahuluan}

Berdasarkan data situs $\underline{w w w}$. tradingeconomics.com, perekonomian Amerika Serikat (AS) menjadi ekonomi terbesar di dunia dengan menempati porsi $21,3 \%$ dari total Gross Domestic Product (GDP) dunia, kemudian diikuti oleh Uni Eropa 13,6\%, China 12,8\%, Jepang 5,7\% dan Inggris sebesar $3,01 \%$, dengan total dominasi keempat negara tersebut sebesar $56,41 \%$ dari total GDP dunia sebesar 87.839 Miliar USD. Dengan mencermati porsi GDP dunia tersebut dan semakin terintegrasinya perekonomian dunia, maka apabila terdapat perubahan ekonomi global dapat berupa pelonggaran atau pengetatan likuiditas pada negara maju akan berpengaruh terhadap negara-negara emerging market seperti Brazil, Rusia, India, Indonesia, dan Afrika Selatan yang memiliki porsi sebesar $7,48 \%$ dari total GDP Dunia. Pengaruh akan semakin membesar manakala negara emerging market sangat tergantung perekonomiannya terhadap salah satu negara maju tersebut. Fratzscher et al. (2013) dalam penelitiannya menunjukkan bahwa tindakan The Federal Reserve (The Fed) pada fase awal krisis berupa kebijakan Quantitaive Easing 1 (QE1) dan Quantitaive Easing 2 (QE2) sangat efektif dalam menurunkan tingkat yield obligasi dan meningkatkan pasar ekuitas terhadap negara lain. Sementara Belke et al. (2017) telah melakukan penelitian sejauh mana perubahan yield obligasi negara maju dalam mempengaruhi yield obligasi pemerintah di negara emerging asia. Dengan menggunakan Variance Decomposition, hasilnya menunjukkan bahwa yield obligasi di negara emerging asia merespon secara signifikan terhadap perubahan yield obligasi AS dan Eropa dengan kekuatan yang heterogen antar negara.

Sementara itu, berdasarkan data situs www.worldbank.org, pertumbuhan ekonomi dunia dalam kurun waktu 20122016 cenderung stabil berada pada kisa- ran 2,4\%-2,8\%. Posisi ini lebih rendah dibandingkan pertumbuhan ekonomi tahun 2010 dan 2011 yang tercatat 4,3\% dan $3,1 \%$, sedangkan saat krisis keuangan pada tahun 2009 tercatat pertumbuhan ekonomi sebesar $-1,7 \%$. Apabila dibandingkan periode krisis ekonomi awal tahun 1990an dan krisis 1998-2001 di kawasan Asia, maka perbaikan ekonomi setelah krisis kurun waktu 2012-2016 berjalan lebih lambat dibandingkan periode sebelumnya. Hal ini dapat diamati dengan data pertumbuhan ekonomi periode setelah krisis 1990an ataupun 1998-2001 yang tercatat meningkat sekitar 3-4,5\%.

Untuk mendorong adanya perbaikan pertumbuhan ekonomi, berbagai kebijakan telah diambil oleh bank sentral di negara maju. Selama beberapa tahun, bank sentral di negara maju menerapkan kebijakan suku bunga acuan hampir mencapai 0\% bahkan untuk Jepang telah menerapkan suku bunga acuan minus $0,1 \%$ pada awal tahun 2016 yang secara historis belum pernah diterapkan oleh Bank of Japan sebelumnya. Untuk semakin mempercepat efek penurunan tingkat suku bunga terhadap pertumbuhan ekonomi, juga diterapkan program QE melalui pembelian aset jangka panjang seperti The Fed melakukan pembelian UST, Mortgage-Backed Securities (MBS), dan utang bank pada tahun 2008-2013. Bank of Japan dan European Central Bank juga melakukan $\mathrm{QE}$, yang berdasarkan data Deutsche Bank Global Market tercatat kedua bank sentral tersebut ratarata setiap bulan melakukan $\mathrm{QE}$ sebesar 180 miliar USD sejak tahun 2015. Batten et al. (2006) telah menyelidiki global bond yang dikeluarkan oleh pemerintah China, Korea, Malaysia, Filipina dan Thailand dan mencocokan dengan yield UST tenor 2, 5, 10 tahun dengan metode GARCH. Hasilnya menunjukkan bahwa perubahan yield curve ON negara tersebut terkait perubahan Fed Fund Rate.

Namun demikian, dengan per- 
tumbuhan ekonomi AS yang membaik, maka The Fed telah mengambil kebijakan pengurangan stimulus ekonomi (tapering off) di awal tahun 2014 dan normalisasi kebijakan dengan menaikkan suku bunga acuan dari 0\% sejak 2006 menjadi 0,25\%0,50\% pada Desember 2015 dan terakhir naik menjadi $1,25 \%-1,5 \%$ pada bulan Desember 2017. Hal ini sebagai babak awal pengetatan likuiditas global yang berpengaruh terhadap koreksi aliran dana ke negara-negara emerging market yang berdampak pada tekanan pada pasar keuangan domestik setiap menjelang rilis kenaikan Fed Fund Rate. Misra et al. (2014) telah menganalisis reaksi pasar terhadap pengumuman The Fed pada tahun 2013-2014 yang berkaitan dengan tapering off dan kaitannya dengan fundamental ekonomi makro. Penelitian menemukan bukti terdapat perbedaan respon antar berbagai negara selama periode volatilitas tersebut. Negara dengan fundamental ekonomi makro yang kuat, pasar keuangan yang lebih dalam, mengalami depresiasi mata uang yang lebih kecil dan kenaikan yield obligasi negara yang lebih kecil. Respon yang sama juga terjadi untuk pasar saham. Dalam penelitian ini juga menemukan bahwa negara yang memiliki hubungan dagang yang kuat dengan China dapat membantu meredam reaksi pasar dengan catatan tidak terdapat kabar buruk terkait ekonomi China.

Sementara itu data Direktorat Jenderal Pembiayaan dan Risiko Kementerian Keuangan per 24 Oktober tahun 2017 menunjukkan bahwa posisi non residen (asing) merupakan pemegang terbesar SBN yang dapat diperdagangkan dengan porsi 39,19\% (Rp 809,27 Triliun), sedangkan sisanya dimiliki oleh Bank Umum 29,45\% (Rp 608,11 Triliun), Asuransi 12,67\% (Rp261,74 Triliun), Dana Pensiun 4,19\% (Rp 86,52 Triliun), Individu 2,57\% (Rp 53,04 Triliun) dan Bank Indonesia 1,42\% (Rp 29,2 Triliun). Dengan porsi kepemilikan asing yang begitu besar, maka posisi yield SBN sangat rentan terjadi sudden reversal apabila terjadi perubahan kondisi ekonomi global khususnya kebijakan pengetatan likuiditas. Moore et al. (2013) telah melakukan penelitian apakah pembelian aset skala besar oleh The Fed mempengaruhi arus modal keluar dari AS dan dana masuk ke emerging market, juga menganalisis pengaruh imbal hasil UST terhadap yield obligasi negara emerging market. Dengan menggunakan data panel dari negara emerging market, hasilnya menunjukkan bahwa pengurangan 10 basis poin yield UST berdampak kenaikan kepemilikan asing sebesar $0,4 \%$ dari total utang negara emerging market yang berakibat mengurangi yield obligasi negara emerging market. Untuk menguji estimasi hasil penelitian, maka digunakan kembali metode VAR dan hasilnya hampir sama dengan metode data panel, dengan efek yang sangat bervariasi di negara emerging market.

\section{Metodologi Penelitian}

Penelitian ini menggunakan data sekunder yang dikumpulkan oleh Bloomberg berupa data harian dari bulan Januari 2012 sampai dengan Desember 2017. Metode analisis dalam penelitian ini adalah VECM dengan menggunakan sistem variabel runtut waktu. VECM merupakan model yang terestriksi yang disebabkan data tidak stasioner pada tingkat level namun terdapat kointegrasi. VECM merestriksi hubungan jangka panjang variabel endogen agar terjadi konvergen ke dalam hubungan kointegrasinya, namun tetap membiarkan dinamisasi jangka pendek. Selain melakukan metode VECM juga dilakukan analisa impulse respon function dan variance decomposition untuk keperluan analisis peramalan. Adapun spesifikasi VECM secara matematis ditunjukan oleh persamaan sebagai berikut :

$\Delta y_{t}=\mu_{0 t}+\mu_{1 x} t+\pi_{x} y_{t-1}+\sum_{i=1}^{k-1} r_{i x} y_{t-1}+e_{t}$ 
Dengan mengacu persamaan matematis VECM dan mengadaptasi model penelitian Afonso dan Silva (2017) dan Naidhu et al. (2016), Maka untuk menganalisis hubungan antara yield SBN Indonesia dengan faktor makro ekonomi lainnya, maka model persamaan dinyatakan sebagai berikut :

$$
\begin{aligned}
\text { IDGB }_{\mathrm{t}}=\sum_{\mathrm{j}=1}^{\mathrm{k}-1} \mathrm{r}_{\mathrm{ix}} \ln \operatorname{lnSDIDR}_{\mathrm{t}-1}+\sum_{\mathrm{i}=1}^{\mathrm{k}-1} \mathrm{r}_{\mathrm{ix}} \text { IBOR }_{\mathrm{t}-1} \\
+\sum_{\mathrm{j}=1}^{\mathrm{k}-1} \mathrm{r}_{\mathrm{ix}} \mathrm{CDS}_{\mathrm{t}-1}+\sum_{\mathrm{i}=1}^{\mathrm{k}-1} \mathrm{r}_{\mathrm{ix}} \ln _{\mathrm{il}} \text { Price }_{\mathrm{t}-1} \\
+\sum_{\mathrm{j}=1}^{\mathrm{k}-1} \mathrm{r}_{\mathrm{ix}} \mathrm{UST}_{\mathrm{t}-1}+\sum_{\mathrm{j}=1}^{\mathrm{k}-1} \mathrm{r}_{\mathrm{ix}} \text { ONBrazil }_{\mathrm{t}-1}+\mathrm{e}_{\mathrm{t}}
\end{aligned}
$$

Dimana LNUSDIDR merupakan nilai tukar USD/IDR dalam bentuk logaritma natural, JIBOR adalah suku bunga Pasar Uang Antar Bank tenor 3 bulan, CDS adalah Credit Default Swap tenor 10 tahun, LNOil Price adalah harga minyak dunia dalam bentuk logaritma natural, UST adalah yield UST tenor 10 tahun, dan ON Brazil adalah yield ON Brazil tenor 10 tahun.

\section{Hasil dan Pembahasan}

Sebelum melakukan estimasi VECM perlu dilakukan uji stasioneritas data terlebih dahulu. (Gujarati, 2003) berpendapat stasioneritas data terjadi apabila varian dan nilai rata-ratanya dalam berbagai lag berbeda terjadi konstan sepanjang waktu. Dengan menggunakan Augmented Dickey Fuller (ADF) test pada tingkat level maupun tingkat first difference pada series data harian dari tahun 2012:1 sampai dengan tahun 2017:12, hasilnya menunjukkan hanya data CDS stasioner pada tingkat level karena probability <0,05. Oleh karena tidak semua variabel stasioner pada tingkat level, maka harus dilakukan uji stasioner data pada first difference. Hasil tes menunjukkan semua variabel bersifat stasioner pada pada tingkat first difference, dengan hasil pada tabel 1.

Tahap selanjutnya dilakukan penentuan lag optimum dengan menggunakan beberapa kriteria seperti Final Prediction Error (FPE), Likelihood Ratio (LR), Akaike Information Criterion (AIC), Schwarz Information Criterion (SC) dan Hannan- Quin Criterion (HQ). Hasil pemilihan lag optimal atas variabel penelitian terjadi pada lag ke 2, dengan hasil pada tabel 2.

Uji kointegrasi dilakukan untuk mengetahui apakah variabel penelitian memiliki hubungan keseimbangan jangka panjang. Untuk itu, penelitian ini dilakukan uji Johansen untuk melihat ada tidaknya kointegrasi dengan melihat hasil pada uji Likelihood Ratio (LR). Apabila nilai LR $>$ critical value LR atau nilai probability < $0,05(5 \%)$ maka dapat diterima adanya kointegrasi atas sejumlah variabel. Hasil uji kointegrasi atas variabel penelitian diperoleh hasil pada tabel 3.

Tabel 1

Hasil Unit Root Test

\begin{tabular}{lrclccc}
\hline \multirow{2}{*}{ Variabel } & \multicolumn{3}{c}{ Level } & \multicolumn{3}{c}{ First Difference } \\
\cline { 2 - 7 } & \multicolumn{1}{c}{ ADF } & Prob & Keterangan & ADF & Prob & Keterangan \\
\hline LNUSD_IDR & $-1,650266$ & 0,4565 & Tidak Stasioner & $-34,29711$ & 0,000 & Stasioner \\
JIBOR & $-0,984657$ & 0,7606 & Tidak Stasioner & $-20,13667$ & 0,000 & Stasioner \\
CDS & $-3,173593$ & 0,0218 & Stasioner & $-23,65578$ & 0,000 & Stasioner \\
LNOil Price & $-1,148838$ & 0,6981 & Tidak Stasioner & $-36,49036$ & 0,000 & Stasioner \\
UST & $-2,41594$ & 0,1375 & Tidak Stasioner & $-38,65673$ & 0,000 & Stasioner \\
ON Brazil & $-1,436688$ & 0,5655 & Tidak Stasioner & $-36,71098$ & 0,000 & Stasioner \\
SBN Indo & $-1,808298$ & 0,3767 & Tidak Stasioner & $-29,36671$ & 0,000 & Stasioner \\
\hline
\end{tabular}

Sumber: Data Primer Diolah, 2018 
Tabel 2

Hasil Lag Optimum

\begin{tabular}{ccccccc}
\hline Lag & LogL & LR & FPE & AIC & SC & HQ \\
\hline 0 & $-8794,609$ & NA & 0,001991 & 13,64590 & 13,67392 & 13,65642 \\
1 & 10606,75 & 38562,09 & $1,86 \mathrm{e}-16$ & $-16,35776$ & $-16,13365^{\star}$ & $-16,27364$ \\
2 & 10744,21 & 271,7245 & $1,62 \mathrm{e}-16^{\star}$ & $-16,49490^{\star}$ & $-16,07471$ & $-16,33719^{\star}$ \\
3 & 10788,27 & 86,60137 & $1,63 \mathrm{e}-16$ & $-16,48723$ & $-15,87095$ & $-16,25591$ \\
4 & 10818,31 & 58,74328 & $1,68 \mathrm{e}-16$ & $-16,45785$ & $-15,64547$ & $-16,15293$ \\
5 & 10869,44 & 99,40597 & $1,67 \mathrm{e}-16$ & $-16,46115$ & $-15,45268$ & $-16,08263$ \\
6 & 10916,30 & 90,58793 & $1,68 \mathrm{e}-16$ & $-16,45783$ & $-15,25327$ & $-16,00570$ \\
7 & 10949,03 & 62,91906 & $1,72 \mathrm{e}-16$ & $-16,43260$ & $-15,03195$ & $-15,90687$ \\
8 & 10988,26 & $74,99720^{\star}$ & $1,75 \mathrm{e}-16$ & $-16,41745$ & $-14,82071$ & $-15,81812$ \\
\hline
\end{tabular}

Sumber: Data Primer Diolah, 2018

Tabel 3

Hasil Uji Kointegrasi

\begin{tabular}{ccccc}
\hline $\begin{array}{c}\text { Hypothesized } \\
\text { No. of CE(s) }\end{array}$ & Eigenvalue & $\begin{array}{c}\text { Max-Eigen } \\
\text { Statistic }\end{array}$ & $\begin{array}{c}0,05 \\
\text { Critical Value }\end{array}$ & Prob $^{* *}$ \\
\hline None * & 0,059280 & 79,19767 & 46,23142 & 0,0000 \\
At most 1 ${ }^{*}$ & 0,039795 & 52,62891 & 40,07757 & 0,0012 \\
At most 2 & 0,015586 & 20,35855 & 33,87687 & 0,7314 \\
At most 3 & 0,008523 & 11,09372 & 27,58434 & 0,9630 \\
At most 4 & 0,004897 & 6,362675 & 21,13162 & 0,9746 \\
At most 5 & 0,002332 & 3,025722 & 14,26460 & 0,9450 \\
At most 6 & 0,001338 & 1,735008 & 3,841466 & 0,1878 \\
\hline
\end{tabular}

Max-eigenvalue test indicates 2 cointegrating eqn(s) at the 0,05 level

* denotes rejection of the hypothesis at the 0,05 level

**MacKinnon-Haug-Michelis (1999) p-values

Sumber: Data Primer Diolah, 2018

Berdasarkan hasil diatas, terdapat 2 persamaan yang menunjukkan kointegrasi. Dengan demikian metode penelitian yang digunakan adalah VECM. Hasil uji kointegrasi mengindikasikan bahwa pergerakan seluruh variabel memiliki hubungan stabilitas dan kesamaan pergerakan dalam jangka panjang atau seluruh variabel cenderung saling menyesuaikan dalam setiap periode jangka pendek, untuk mencapai ekuilibrium jangka panjang.
Berdasarkan hasil pada Tabel 4 menunjukan bahwa dalam jangka pendek terdapat enam variabel signifikan yaitu SBN Indonesia pada lag 1, CDS lag 1 dan lag 2, UST lag 1 dan lag 2, dan ON Brazil pada lag 1. Adapun untuk UST pada lag 1 berpengaruh positif sebesar $0,20 \%$, artinya jika terjadi kenaikan $1 \%$ pada 1 hari sebelumnya, maka akan menaikkan yied SBN Indonesia sebesar $0,20 \%$ persen pada hari ini. Penjelasan tersebut sebagaimana tercantum dalam tabel dibawah ini : 
Tabel 4

Hasil Estimasi VECM Jangka Pendek dan Jangka Panjang

\begin{tabular}{lcc}
\hline \multirow{2}{*}{ Variabel } & \multicolumn{2}{c}{ Jangka Pendek } \\
\cline { 2 - 3 } & Koefisien & T Statistik \\
\hline D(SBN_INDO(-1)) & 0,099843 & 3,22208 \\
D(CDS(-1)) & 0,001452 & 4,91563 \\
D(CDS(-2)) & 0,000817 & 2,74778 \\
D(UST(-1)) & 0,204501 & 4,17671 \\
D(UST(-2)) & 0,109062 & 2,20733 \\
D(ON_BRAZIL(-1)) & 0,055872 & 3,47925 \\
\hline \multicolumn{1}{c}{ Variabel } & Jangka Panjang \\
\cline { 2 - 3 } & Koefisien & T Statistik \\
\hline LNUSD_IDR(-1) & $-72,74275$ & $-5,51491$ \\
CDS(-1) & $-0,173026$ & $-7,94364$ \\
LNOIL_PRICE(-1) & $-22,49079$ & $-4,68165$ \\
ON_BRAZIL(-1) & 3,400430 & 4,65931 \\
\hline
\end{tabular}

Sumber: Data Primer Diolah, 2018

Pada jangka panjang hanya variabel USD/IDR, CDS, Oil Price dan ON Brazil yang mempengaruhi yield SBN Indonesai. Variabel USD/IDR memiliki pengaruh negatif terhadap yield SBN Indonesia sebesar -72,74275. Artinya, jika USD menguat sebesar satu persen maka akan menyebabkan yield SBN Indonesia turun sebesar $72,74 \%$. Hal ini dapat dimaknai bahwa pergerakan yield SBN Indonesia lebih banyak digerakkan oleh investor asing, dengan demikian investor asing akan sangat senang apabila USD/IDR mengalami penguatan, oleh karena kaitannya dengan harga perolehan saat pembelian SBN dan keuntungan selisih kurs ketika melakukan penjualan SBN. Pengaruh negatif ini selaras penelitian Kurniasih dan Restika (2015) dan Fratzscher et al. (2013). Sedangkan apabila yield ON Brazil naik sebesar satu persen maka yield SBN Indonesia akan ikut naik sebesar $3,4 \%$. Hal ini dapat diartikan bahwa investor akan selalu membandingkan yield SBN Indonesia dengan yield obligasi negara emerging market lainnya untuk akan memaksimalkan keuntungan yang diperoleh dari investasi yang dilakukannya. Hal ini sejalan penelitian Belke et al. (2017), Batten et al. (2006) dan G Min (1998). Apabila harga minyak naik sebesar satu persen maka yield SBN Indonesia akan mengalami penurunan sebesar $22,49 \%$. Pengaruh negatif disebabkan belum tumbuhnya perekonomian dunia yang ditandai harga minyak dunia yang relatif rendah berkisar pada harga 3060 US Dollar per Barel, sehingga tekanan eksternal mampu mendorong naiknya yield SBN Indonesia. Hal ini selaras dengan penelitian Abeysinghe (2001) terkait respon harga minyak terhadap negara maju dan negara kecil dengan perekonomian terbuka. Adapun untuk CDS Indonesia memiliki hubungan negatif namun tidak signifikan pengaruhnya hanya sebesar $0,17 \%$ terhadap yield SBN Indonesia. Hal ini sejalan dengan penelitian Fontana dan Scheicher (2010) dalam menganalisa korelasi CDS pada negara-negara eropa dengan pasar obligasi yang menemukan bahwa separuh negara sampel memperhatikan yield obligasi negara dengan melihat CDS dan separuh negara sampel tidak memperhatikan yield obligasi negara melalui harga CDS. 
Muhammad Ichsan, dkk. MediaTrend 13 (2) 2018 p.178-187

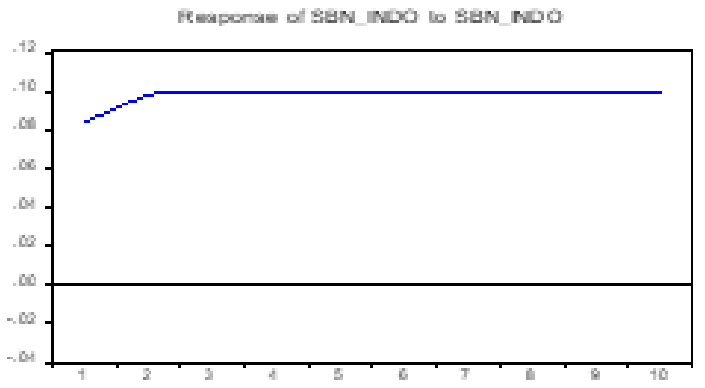

Peaponas of SAN INDO is LNUSD ICR

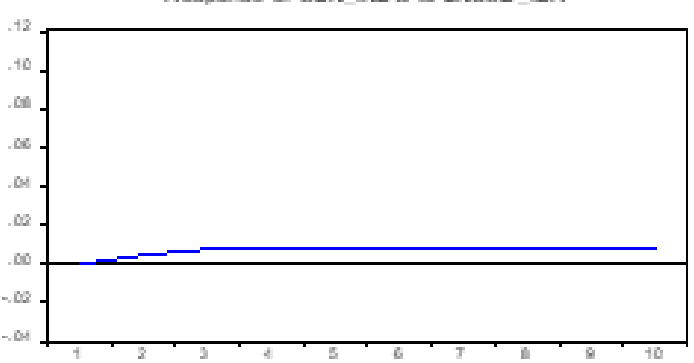

Pesaponse of (a) noo to jeore

Fespons of SAN NOO io COS
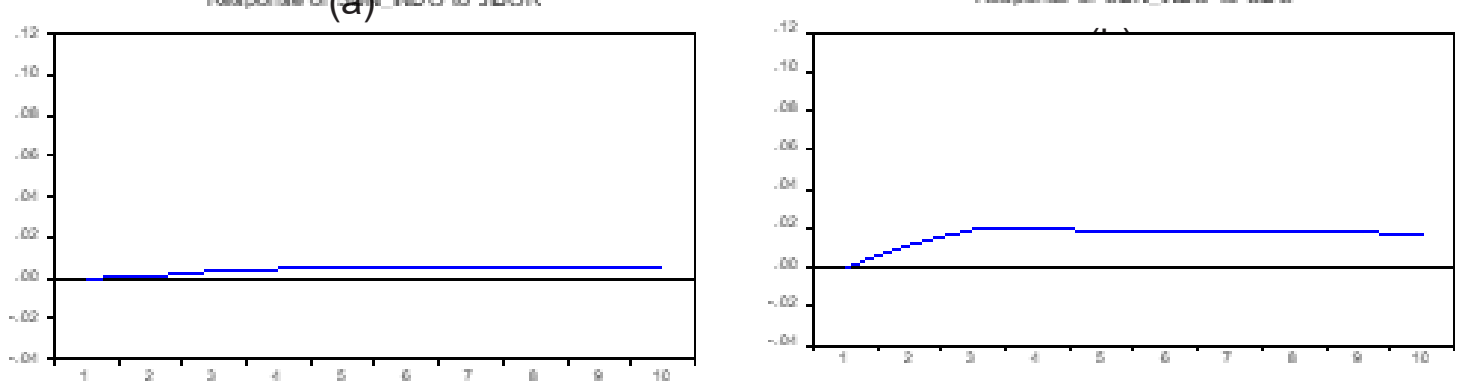

(C) $)^{\text {oo in LnOL Price }}$

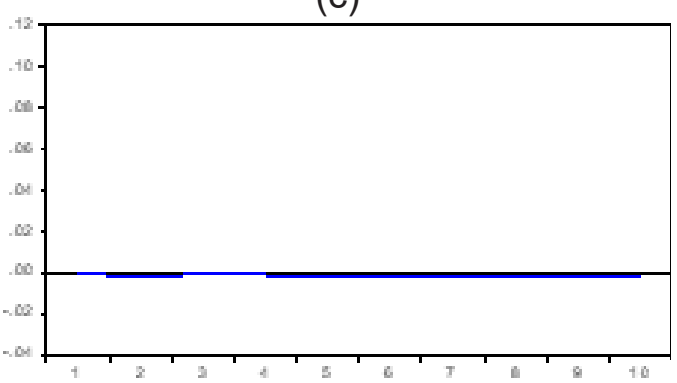

Plesporase of SAN INDO to US?

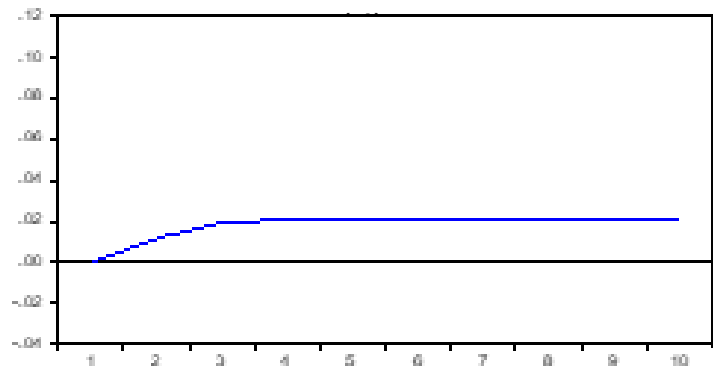

(e)

Pessporise of SBN INDO bo ON BRAZT.

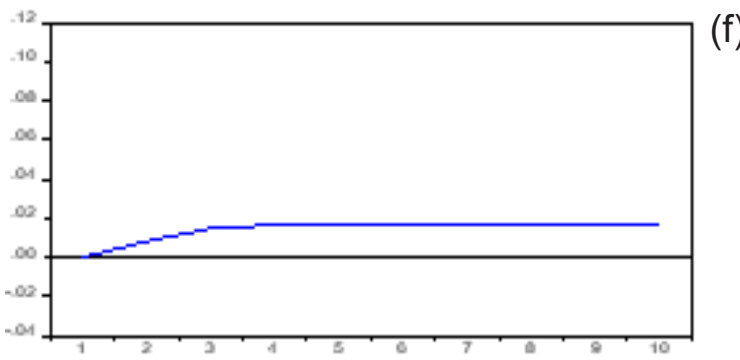

(g)

Gambar 1

Hasil Impulse Response Function 
Gambar di atas menunjukkan respon variabel yield SBN dalam 10 (sepuluh) periode kedepan apabila terjadi shock pada variabel yield SBN sendiri, maupun variabel lainnya, yang dijelaskan bahwa Gambar 1 huruf (a) shock 1 (satu) standar deviasi yield SBN direspon secara positif pada periode 1 sebesar $0,08 \%$ dari variabel itu sendiri. Pengaruh shock tersebut terus meningkat terbatas setiap periodenya dengan nilai pada periode 10 menjadi sebesar 0,99\%.

Gambar 1 huruf (b) menunjukkan bahwa shock sebesar 1 (satu) standar deviasi oleh nilai tukar USD/IDR tidak direspon oleh kenaikan yield SBN pada lag 1, namun pada periode setelahnya mengalami kenaikan menjadi $0,008 \%$ dan cenderung stabil sampai dengan periode 10 . Gambar 1 huruf (c) menunjukkan bahwa shock sebesar 1 (satu) standar deviasi oleh JIBOR tidak direspon pada periode 1 , namun pada periode setelahnya mengalami kenaikan pada periode 2 menjadi 0,001\% dan cenderung naik terbatas sampai dengan periode 10 sebesar 0,005\%. Gambar 1 huruf (d) menunjukkan bahwa shock sebesar 1 (satu) standar deviasi oleh CDS Indonesia tidak direspon pada periode 1. Namun pengaruh shock meningkat pada periode 2 sebesar $0,01 \%$ dan cenderung stabil sampai periode 10 . Hal ini artinya investor akan selalu melihat pergerakan dari probability of default sebagai cara yang termudah atas kemungkinan kebangkrutan dari suatu negara, dengan naiknya CDS maka akan diikuti kenaikan yield ON. Gambar 1 huruf (e) menunjukkan bahwa shock sebesar 1 (satu) standar deviasi pada oil price tidak direspon pada periode 1. Namun pada periode selanjutnya direspon secara negatif dengan nilai $0,001 \%$ pada periode 2 dan cenderung stabil sampai dengan periode 10. Respon negatif atas shock oil price dapat diartikan bahwa naiknya oil price sebagai tanda adanya optimisime perbaikan pertumbuhan ekonomi dunia yang gilirannya akan berpengaruh terhadap turunnya yield SBN. Namun demikian, hubungan negatif ini kemungkinan disebabkan oil price pada periode 2012-2017 yang mengalami penurunan dan berada dikisaran 30-60 USD per Barel. Akan tetapi hasil penelitian akan lain jika harga minyak berada pada kisaran lebih dari 80 USD/Barel maka arah yield SBN dengan harga minyak akan positif searah, mengingat status Indonesia sebagai negara nett imported minyak.

Gambar 1 huruf (f) menunjukkan bahwa shock sebesar 1 (satu) standar deviasi oleh US Treasury tidak direspon pada periode 1 namun respon mengalami kenaikan pada periode 2 sebesar $0,01 \%$, naik menjadi $0,02 \%$ pada periode 4 dan stabil sampai periode 10. Dari seluruh variabel penelitian shock US Treasury memberikan pengaruh terbesar atas yield SBN Indonesia. Hal ini artinya investor akan melihat US Treasury sebagai acuan kearah mana yield SBN akan bergerak. Gambar 1 huruf (g) menunjukkan bahwa shock sebesar 1 (satu) standar deviasi oleh yield ON Brazil tidak direspon pada periode 1. Namun pengaruh shock terus meningkat pada periode-periode berikutnya, dan pada periode 3 dengan nilai sebesar 0,014\% dan cenderung stabil dikisaran 0,017\% pada periode 10 . Hal ini memiliki arti bahwa dengan adanya shock kenaikan yield ON Brazil maka akan direspon kenaikan yield SBN, oleh karena size ekonomi Brazil dan Indonesia pada posisi yang tidak jauh berbeda dan termasuk negara emerging market, dan seorang investor pasti akan membandingkan berapa nilai yield yang akan diterima dan tingkat risikonya apabila investasi di Brazil, Indonesia atau negara emerging market lainnya dan yield pada negara maju seperti AS, Eropa dan Jepang. 


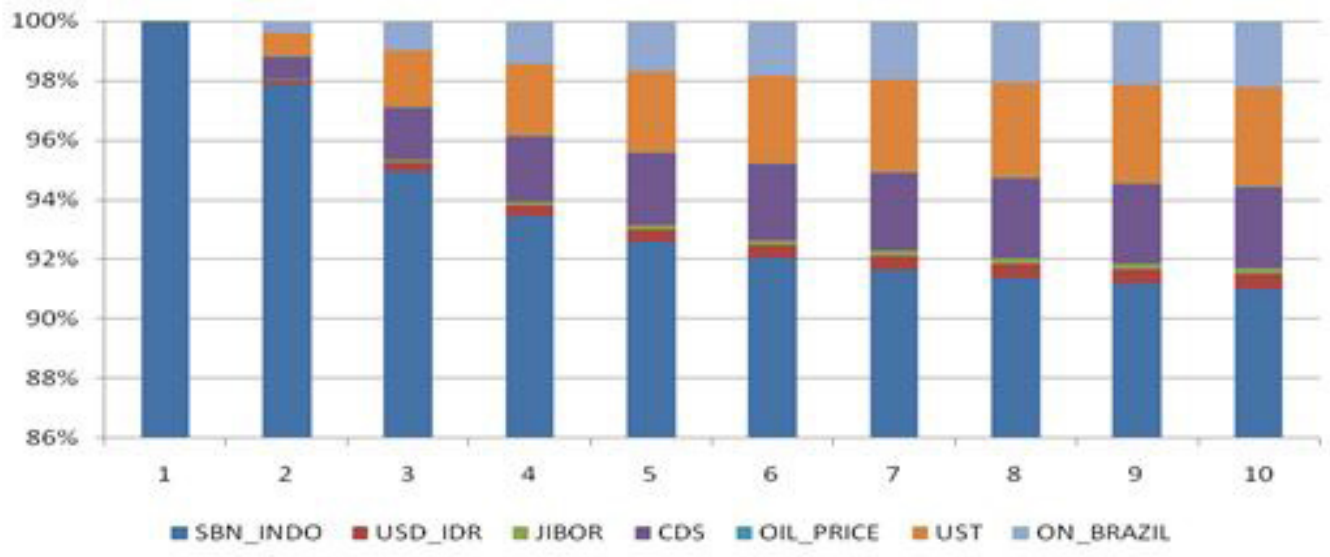

Gambar 2

Hasil Forecast Error Variance Decompositon (FEVD)

Hasil analisis FEVD dalam gambar 2 dapat terlihat bahwa variabel yield SBN menjelaskan bahwa pada periode ke 1 dipengaruhi oleh variabel itu sendiri yaitu $100 \%$. Namun pada periode ke 2 nilainya terus menurun sampai sampai periode 10 menjadi sebesar $91,01 \%$. Kontribusi shock variabel yield ON Brazil terhadap yield SBN mula-mula hanya sebesar 0 persen pada periode 1 dan terus mengalami peningkatan sampai periode ke-10 menjadi sebesar $2,22 \%$. Kontribusi shock variabel oil price terhadap yield SBN tahun mula-mula $0 \%$ pada periode 1 dan mengalami peningkatan kontribusi yang tidak signifikan sampai periode 10 hanya $0,01 \%$. Sementara hasil pengujian variance decomposition untuk variabel CDS menyatakan bahwa kontribusi shock variabel CDS terhadap yield SBN terus meningkat sampai periode ke 10 sebesar $2,26 \%$. Sementara itu, shock variabel JIBOR memiliki kontribusi yang tidak signifikan dimana sampai period ke 10 hanya sebesar $0,21 \%$. Adapun untuk US Treasury memiliki kontribusi terbesar dan terus meningkat sampai periode 10 sebesar 3,35\%, sedangkan untuk kontribusi USD/IDR memiliki kontribusi sebesar $0,49 \%$ pada periode ke 10 dan dengan kenaikan antar periode cenderung naik terbatas.

\section{Penutupan}

Analisis VECM terlihat bahwa dalam jangka panjang hanya variabel USD/IDR, Oil Price, dan CDS berpengaruh negatif terhadap yield SBN, adapun ON Brazil berpengaruh positif terhadap yield SBN. Berdasarkan analisis IRF dapat terlihat bahwa shock kenaikan yield ON Brazil, CDS, JIBOR, USD/IDR dan UST langsung direspon secara positif oleh yield SBN dengan nilai beragam setiap periodenya. Namun untuk shock yang ditimbulkan oleh Oil Price direspon negatif oleh yield SBN dengan nilai yang tidak signifikan. Kontribusi atas masing-masing variabel masih didominasi oleh dirinya sendiri. Namun, hasil analisis FEVD menunjukkan bahwa variabel UST merupakan variabel terbesar yang memiliki kontribusi pengaruh terhadap yield SBN Indonesia, diikuti nilai CDS Indonesia dan ON Brazil selaku negara kompetitor. Sedangkan variabel lainnya memiliki kontribusi pengaruh namun nilai kontribusinya tidak terlalu signifikan.

\section{Daftar Pustaka}

Abeysinghe, T. (2001). Estimating Direct and Indirect Impact of Oil Price on Growth. Economics Letters, 73, 147-153.

Afonso, A., \& Silva, J. (2017). Debt Crisis 
and 10-year Sovereign Yields in Ireland and in Portugal. Applied Economics Letters, 1-6.

Batten, J. A., Fetherston, T. A., dan Hoontrakul, P. (2006). Factors Affecting the Yields of Emerging Market Issuers: Evidence from the Asia-Pacific Region. Journal of International Financial Markets, Institutions and Money, 16(1), 57-70.

Belke, Ansgar. , Irina, Dubova., dan Volz, Ulrich. (2017). Bond Yield Spillovers from Major Advanced Economies. SOAS Department of Economics Working Paper No. 203, London : SOAS University of London.

Fontana, A., dan Scheicher, M. (2010). Working Paper Series An Analysis of Euro Area Sovereign CDS and Their Relation with Government Bonds by Alessandro Fontana Working Paper Series No 1271 /December 2010.

Fratzscher, M., Duca, M. Lo, Straub, R., Fratzscher, M., dan Straub, R. (2013). Working Paper Series No 1557 /June 2013 On the International Spillovers of US Quantitative Easing.

Gujarati, Damodar N. Basic Econometrics, 4th edition. 2003

Kurniasih, A., dan Restika, Y. (2015). The influence of Macroeconomic Indicators and Foreign Ownership on Government Bond Yields: A Case of Indonesia. Mediterranean Journal of Social Sciences, 6(5), 34-42.

Min, H. G. (1998). Determinants of Emerging Market Bond Spread : Do Economic Fundamental Matters?. World Bank Research Group, 1-31.

Mishra, P., Moriyama, K., N'Diaye, P., dan Nguyen, L. (2014). Impact of Fed Tapering Announcements on Emerging Markets. IMF Working Papers, 14(109), 1.
Moore, J., Nam, S., Suh, M., dan Tepper, A. (2013). Estimating the Impacts of U.S LSAPs on Emerging Market Economies' Local Currency Bond Markets. Federal Reserve Bank of New York Staff Reports, (595), 1-45.

Naidhu, ASH., Goyari, P., dan Kamaiah, B. 2016. Determinants of sovereign bond yields in emerging economies: Some panel inferences. Theoretical and Applied Economics Volume XXIII (3), 101-118. 